\title{
絹フィブロインの高圧示差熱分析
}

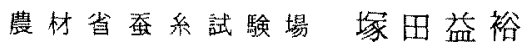 \\ 東京農工大学工学部平林潔 \\ 東京工業大学高分子工学科甲本忠史・河合徹
}

\section{DIFFERENTIAL THERMAL ANALYSIS OF SILK FIBROIN THREAD UNDER HIGH PRESSURES OF NITROGEN}

\author{
By Masuhiro Tukada*, Kiyoshi Hirabayashi**, Tadashi Komoto ${ }^{* * *}$ and Toru Kawai ${ }^{* * *}$
}

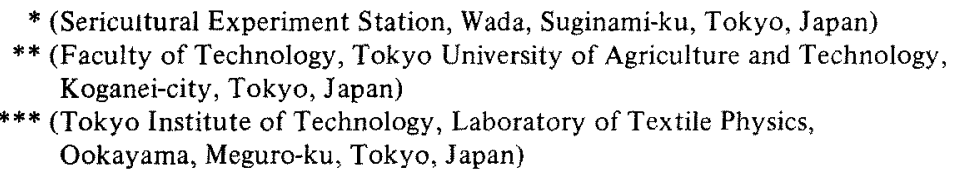

The effect of the nitrogen pressure up to $61 \mathrm{~kg} / \mathrm{cm}^{2}$ on the thermal properties of silk fibroin was studied. Differential thermal analysis (DTA) run was taken at the heating rate of $10^{\circ} \mathrm{C} / \mathrm{min}$. The DTA curve of a silk fibroin thread showed a single endothermic peak at ca. $319^{\circ} \mathrm{C}$ under the pressure of $1.0 \mathrm{~kg} / \mathrm{cm}^{2}$ This peak is due to the thermal decomposition of the silk fibroin. The peak was splitted into two and the lower main peak temperature was shifted to lower temperature with the increasing pressure. Under the pressure of $61 \mathrm{~kg} / \mathrm{cm}^{2}$, the DTA curve of a silk fibroin showed an initial endothermic peak at $300^{\circ} \mathrm{C}$ and second endothermic peak at $326^{\circ} \mathrm{C}$. The lower endothermic peak temperature agreed well with the single peak temperature obtained for the specimen contracted by immerging the original specimen in aqueous $\mathrm{LiBr}$ solution $(70 \%)$ at $25^{\circ} \mathrm{C}$. The birefringence of the specimen decreased down to $46 \%$ of the original silk fibroin. On the other hand, the silk fibroin hydrolyzed by aqueous $\mathrm{HCl}$ solution showed an endothermic peak at ca. $320^{\circ} \mathrm{C}$. This temperature agreed with the higher endothermic peak temperature.

The temperature at which the decomposition began was shifted to lower temperature with increasing the pressure of nitrogen. It was also found that a drastic shrinkage of the silk fibroin thread occurred in a temperature range of 300 to $330^{\circ} \mathrm{C}$, accompanying a conformational change from $\beta$ to random coil. From these results, it may be concluded that the endothermic peak appeared at around $300^{\circ} \mathrm{C}$ is attributed to the thermal decomposition of the amorphous $\beta$ structure of silk fibroin and that the endothermic peak at $326{ }^{\circ} \mathrm{C}$ is due to the decomposition of silk fibroin with the crystalline $\beta$ structure.

(Received December 26, 1977)

\section{1.はじめに}

高无示差熱分析は測定雾囲気の王力を 1 気压以上にし, 物頁の熱的挙動を調へるととを目的としている。この測 定では雾囲気の圧力を增加ざせることにより熱伝導率が 上るため，常圧では観察されない別の熱的举動が期待で
きる゙。われわれは絹フィブロインの熱分析を行い，絹 の構造と物性について研究を進めてきだ, ${ }^{3)}$ 。本報告は 高代示差熱分析により絹フィブロインの熱的挙動を調べ， 約 $320^{\circ} \mathrm{C}$ に見れる吸熱ピークが測定第围気 ( $\mathrm{N}_{2}$ ガス) 王

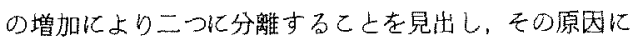
ついて考察したものである。 


\section{2. 試料および塞験方法}

\section{1 試 料}

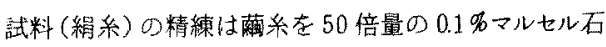

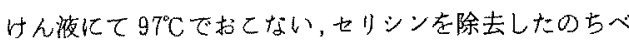
ンゼンメタノール(体積比 $2: 1$ ) の混液を溶媒とし, ソ ックスレー抽出器でワックス等を除去した李のである。 収縮絹系は濃度之異なる $\mathrm{LiBr}$ 水溶液で絹系 24 時間処 理し，収縮後定長下で水洗乾燥さ廿たものである。また 收縮率は $\left(l_{0}-l\right) / l_{0}$ で示した。ただし $l_{0}$ は原長，はは 収縮後の長さである。

\subsection{1 高压示差熱分析 (高任DTA)}

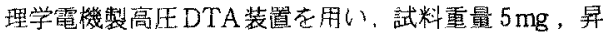
温速度 $10^{\circ} \mathrm{C} / \mathrm{min}$ ，DTA感度 $\pm 25 \mu \mathrm{V}$ で実験を行った。

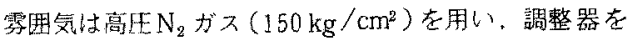
通して所定の死力を保った。

2.2.2 熱重量分析 ( TG) - 示美熱分析 (DTA) 同時 測定装置

理学電機製䒾置を用い，試料 $10 \mathrm{mg}$ ，异温速度 $10^{\circ} \mathrm{C} /$ min， TGのフルスケール10mg，DTAの測定感度は $\pm 50 \mu \mathrm{V}$ で実験を行った。

\subsection{3 熱機械的分析 (TMA)}

理学電機製装置を用い系長 $10 \mathrm{~mm}$, 引張り荷重 $3 \mathrm{mg}$ ， 昇温速度 $10^{\circ} \mathrm{C} / \mathrm{min}$ ，フルスケール2000ルで寸法变化を 測定した。

\subsection{4 屁折率心測定}

$20 \pm 0.1^{\circ} \mathrm{C}$ 亿おいて，アッべの屈折計を用いつぎの方 法で行った。漫液として届折率を 0.002 とびに調整した ブチルステアレート。トリクレジルホスフェート战よひ トリクレジルホスフェート.ジフェールアミンの湦合液 を使用し，ベッケ法により $n_{/ /}$， n」を個々に測定し複屈 折を求め大。

\section{3. 害駿結果および考察}

\section{1 絹フィブロインの高压DTA}

高压DTAの測定雾囲気 $\left(\mathrm{N}_{2}\right.$ ガス) の压力を変元，絹

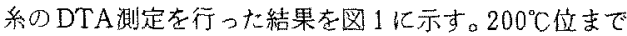
のDTA曲線には顯著な变化はみられないが、をれ以上 の温度領域では，分解吸熱ピークの熱的挙動に興味のあ る現象がみられた。

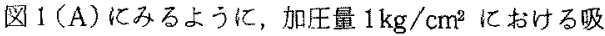
熱ピークは $319^{\circ} \mathrm{C}$ 亿現れるが， $\mathrm{N}_{2}$ ガス加王範囲が 1 $\mathrm{kg} / \mathrm{cm}^{2}$ に扎てては压力の增加に上り徐々にピーク温度 が低温側に移行する。さらに21 kg/ $\mathrm{cm}^{2}$ 以上（図 $1, D$,

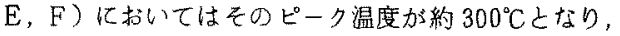
ほとんじ一定の吸熱ピーク温度を示すようになる。なお

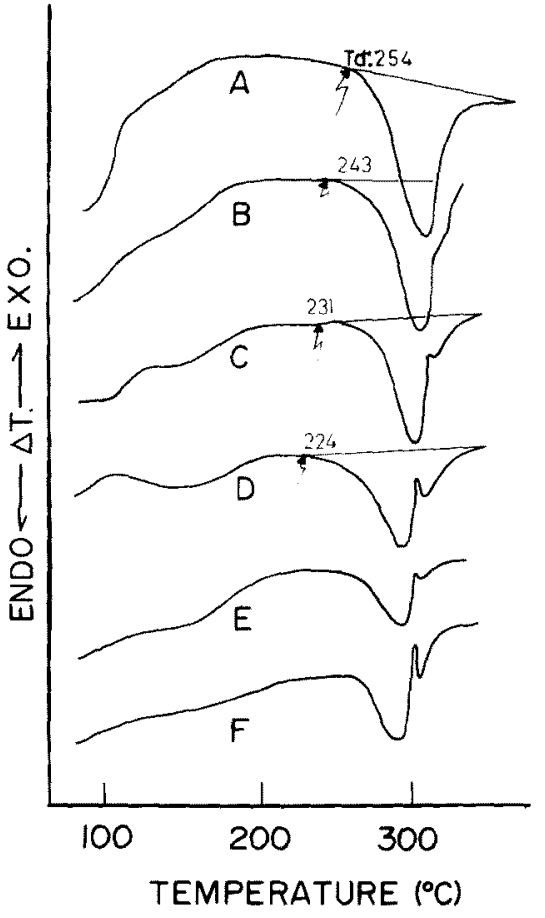

Fig. 1. DTA curves of silk fibroin threads under high pressures of nitrogen: Nitrogen pressure

A $1 \mathrm{~kg} / \mathrm{cm}^{2}$;

B $3 \mathrm{~kg} / \mathrm{cm}^{2} ;$ C $6 \mathrm{~kg} / \mathrm{cm}^{2}$;

D $21 \mathrm{~kg} / \mathrm{cm}^{2} ; \quad$ E $41 \mathrm{~kg} / \mathrm{cm}^{2}$;

F $61 \mathrm{~kg} / \mathrm{cm}^{2}$

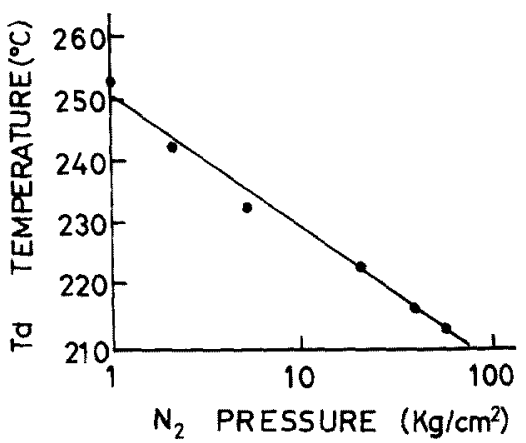

Fig. 2. The relation between the pressure of nitrogen and the temperature, $T_{d}$, at which the endothermic process started. 
図1，(B)のDTA曲線には第 1 ピークの高温側に小さな 第2のピーク $\left(326^{\circ} \mathrm{C}\right.$ の吸熱ピーク)加認力られる。この ピークは雹囲気の死力が増加すると次第に鋭いピークを なり，低温側 $\left(314^{\circ} \mathrm{C}\right)$ に移行する。

$\mathrm{N}_{2}$ ガスの加生による吸熱開始温度 $\left(T_{d}\right)$ の变化を図 2 に示す。測定雾囲気である $\mathrm{N}_{2}$ ガスの霰囲與の圧力が 61 $\mathrm{kg} / \mathrm{cm}^{2}$ のとき $T_{\mathfrak{d}}$ は $213^{\circ} \mathrm{C}$ よる。しれは $1 \mathrm{~kg} / \mathrm{cm}^{2} の$ 加生時の $263^{\circ} \mathrm{C}$ に較へ $50^{\circ} \mathrm{C}$ 低下している。また加止量の 增大とともに $T_{d}$ はほぼ直線的に減少する。

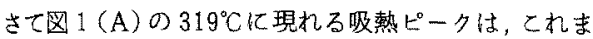
での研究から融解を之もなう䋩フィブロインの熱分解に よる6のである゙2。従って図、，図2の結果加，絹フ ィブロインの熱分解は测定雾围気の王力が増すにつれて, より低温度で起ることがわかる。すなわち， $\mathrm{N}_{2}$ Eの增大 にともな上上記の熱的性質の変化は $\mathrm{N}_{2}$ ガスによるつィ プロインの何ら加の構造变化を反映していると言えよう。

\subsection{TGおよびTMA}

つぎ測定雾国気の死力の增加により吸熱ピークが二 つに分離してゆく現象を解明するために綃フィブロイン の熱重量分析 (TG) および熱機械的分析 (TMA) 拉 てない検討した。まず $\mathrm{N}_{2}$ ガス加圧量が $1 \mathrm{~kg} / \mathrm{cm}^{2} の$ とを の䋧フィブロインのTG-DTA曲線を図3に示す。DTA ではフィブロインの熱分解反伈に対応する温度は $315^{\circ} \mathrm{C}$ に現㣗，図 1 (A)にみられた温度 $\left(319^{\circ} \mathrm{C}\right)$ とほぼ一致 する。とれは加圧量が $1 \mathrm{~kg} / \mathrm{cm}^{2}$ 程度では絹フィブロイ

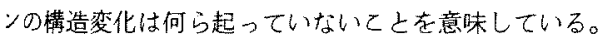
ととろで四 $に$ においてDTA曲線の $70^{\circ} \mathrm{C}$ 近边にみられる 㨽広い吸熱ピークは試料中に吸着していた水分の脱触に よるすのである ${ }^{2)}$ 。らに熱重量减少は $270^{\circ} \mathrm{C}$ 近辺より 徐々に起るが，急激な重量減少は $290^{\circ} \mathrm{C}$ 以上でみられ， 吸熱ピーク $\left(315^{\circ} \mathrm{C}\right)$ が現れる温度でのフィブロイン残量 は約 70\%であり，その近辺で分解速度は最大になるとと がわかる。 $\mathrm{N}_{2}$ 加压による絹フィブロインの熱的性質の

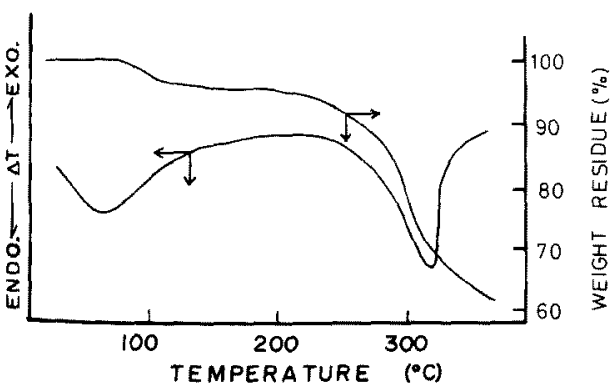

Fig. 3. TG and DTA curves measured simultaneously for a silk fibroin thread under nitrogen pressure of $1 \mathrm{~kg} / \mathrm{cm}^{2}$

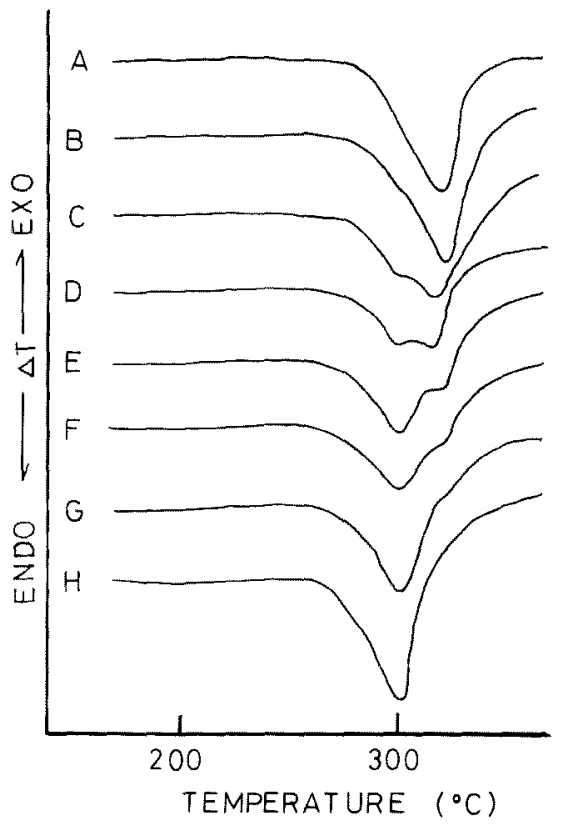

Fig. 4. DTA curves of silk fibroin threads contracted by immersing the specimen in aqueous $\mathrm{LiBr}$ solution at $25^{\circ} \mathrm{C}$.

Percent contractions are $0 \%(\mathrm{~A}), 10 \%$ (B), $30 \%$ (C), 40\% (D), 50\% (E), 60\% (G) and $70 \%(\mathrm{H})$.

变化が構造変化に起因すると考え、フィブロインの化学 的処理による棰造变化すお拈， $\mathrm{LiBr}$ 水溶液に上って 収縮させた縝系について常圧てのDTA測定を行った。 四4亿見る上うに，収縮率0\%すなっち原系化現れた吸 熱ピークは收縮率の増大上之もに二つに分れ，高温側の 小さいピーク温度は取縮率0\%の綟系のそれ之一致する

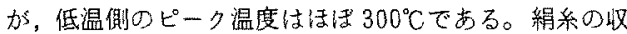
縮摔加增し 60，70\%になる，ほ亡んど低温側ピークの

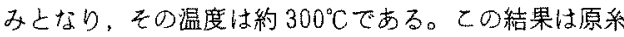
$の \mathrm{~N}_{2}$ 老用いた高压DTAの結果(図1)と類似している ことから， LiBr 水溶液に上る絹杀の収縮は $\mathrm{N}_{2}$ による 構造変化と類似しているよ考えられる。

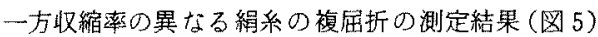
による上，収縮摔が60拈よび70\%のときは0\%の上き にくら゙゙をれぞれ，58杖よび46\%まで複屆折が低下す るのが認められる。このとと加ら収縮率が增すと配向の よいß銷はランダム化し，その吸熱ピークは $320^{\circ} \mathrm{C}$ 加 $300^{\circ} \mathrm{C}$ に移行したものと思われる。収縮系の構造を詳細 に調へるために，TMA測定行った。图6に原系（B) および70\%収縮系（A）のTMA曲線を示す。原系（B) 


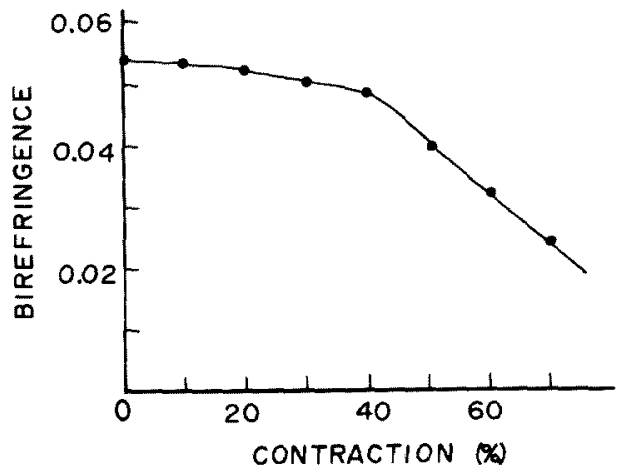

Fig. 5. Relationship between birefringence and percent contraction of silk fibroin threads.

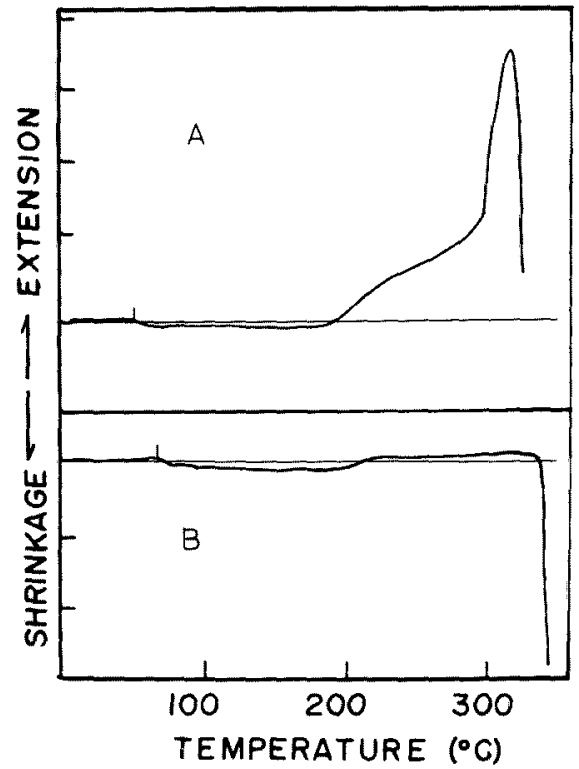

Fig. 6. Thermomechanical analysis of silk fibroin threads contracted by aqueous $\mathrm{LiBr}$ solution at $25^{\circ} \mathrm{C}$. Shrinkage and extension are shown in arbitrary units. Percent contractions of the used samples are 70\% (A) and $0 \%$ (B).

は75号から僅かな収維が，そして $200^{\circ} \mathrm{C}$ 近辺からわずか

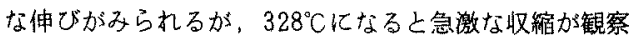

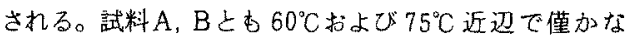
收樎が括てるが後者の場合図 $30 \mathrm{TG}$ の結果と一致し， 両者と屯試料中の吸着水分の脱離にと屯なう構造変化に

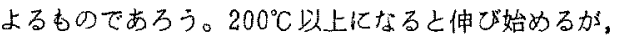

てれはTMA測定に棜りる荷重の効果であることは明ら かである。しかし試料Aはかなり伸長し約 $295^{\circ} \mathrm{CKなる}$ 亡急激化伸長する。乙れは原系に近い構造の再発生に上 る(多分剧所的な結昆化 ( $\beta$ 化)をともなう)自然伸長で あるう。しかし $300^{\circ} \mathrm{C}$ 近辺で原系 (B) 上同しように収縮 してしまう。との高温におりる収縮挙動を明らか伅する ため測定機中において原試料老 $\mathrm{N}_{2}$ 雾团気下 $117^{\circ} \mathrm{C}, 275$ ${ }^{\circ} \mathrm{C}, 300^{\circ} \mathrm{C}$ おど $330^{\circ} \mathrm{C}$ の各温度で 30 尔熱処理したのち とり出し，X線回折によりその分子形態を調へた。その 結果を表1亿示す。すなわ念激な収縮が扣てる前後 $\left(300 \sim 330^{\circ} \mathrm{C}\right)$ に执いて, $\beta$-ランダムコイル転移加起っ ているとよがわかる。

Table 1. Conformation of silk fibroin in a thread at various temperatures.

\begin{tabular}{|l|c|c|c|c|}
\hline Temperature $\left({ }^{\circ} \mathrm{C}\right)$ & 117 & 275 & 300 & 330 \\
\hline Conformation & $\beta$ & $\beta$ & $\beta$ & Random Coil \\
\hline
\end{tabular}

以上のとと加ら収綰率の異なるA，B試料の熱機械的 性兵を次の上うに考察することができる。

フィブロイン分子銧が繊維軸力向に比較的配向した原 系（B）は昇温過程で顕著な収縮，伸瑇の変化を示さない 加，熱分解温度に達すると分子鎖のランダム化とと本に 急激な試料の取縮をきたす。一万70\%収縮絹系（A）は 分子配向度が低いため（国 5)，分子の熱運動か活発にな る $200^{\circ} \mathrm{C}$ 近辺より荷重応力により乱九た分子鎖加次第に 配向し，試料長が徐々に增加したもの上考えられる。 LiBr 水溶液処理に上万程系の配向変化（図 5)，およし， 絹系フィブロインの粉末化試料 ",5) DDTAおよびX線 回折測定の結果などから $300^{\circ} \mathrm{C}$ 近辺の吸熱ピーク（图1 -F)は哭配向 $\beta$ 型の絹フィブロインの熱分解によりお こるものと考えられる。すなわち $\mathrm{N}_{2}$ 加区下における $300^{\circ} \mathrm{C}$ 近辺 $の \mathrm{DTA}$ 曲線の熱举動は，上記の無配向 $\beta$ 型 試料の結果之極的て類做している。従って $\mathrm{N}_{2}$ 加化によ って絹フィブロインは一部無配向 $\beta$ 構造を形成し，てれ 加 $300^{\circ} \mathrm{C}$ 近辺で熱分解すると考元られる。一方塩酸加水

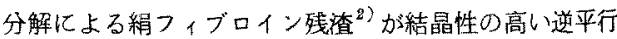

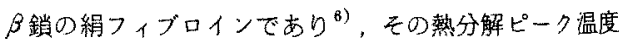

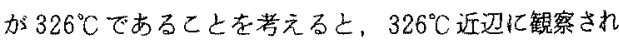
る小さい吸熱ピーク（图 1，D，E，F）結晶性の高い 逆平行 $\beta$ 銷の綟フィブロインのランダムコイルへの軽移 をともなう熱分解に起团するものと結論づけられる。

従って高王DTAにより常匤で現れる䋧フィブロイン ○熱分解ピーク $\left(319^{\circ} \mathrm{C}\right)$ を配向の乱れた成分之配向の上 い队鎖の成行の奇与に分離できたことになる。このよう

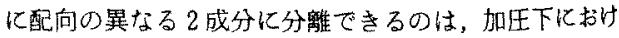
る $\mathrm{N}_{2}$ がポリマー固体中八浸透あるいは溶解するととに 
より，無配向分子銷の運動性か增すため，分解温度の低 下をあたらしたよ考えられよう。

\section{4. 要旨}

絧フィブロインの熱分解におよ拉よ゙す $\mathrm{N}_{2}$ ガス等国気圧 力の影響を調へた。压力は一定保ち，昇温速度 $10^{\circ} \mathrm{C} /$ minで示差熱分析 (DTA)を扢なった。絹フィブロイ ンのDTA曲線は雾囲気の压力が $1 \mathrm{~kg} / \mathrm{cm}^{2}$ の上き，319 ${ }^{\circ} \mathrm{C}$ 比一の吸熱ピークを示し，これは絹フィブロインの

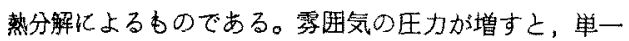
の昨熱ピークの形は变化し，主ピークの温度は低温側に 移動する。臣力が $61 \mathrm{~kg} / \mathrm{cm}^{2}$ となるとDTA曲線上 300 Cおよび $314^{\circ} \mathrm{C}$ Kこつの昅熱ピーク加現れる。低温ピー ク温度は $\mathrm{LiBr}$ 溶液中で $70 \%$ 収縮した絹フィブロインの ピーク温度上一致した。との取縮絹フィブロイン絹系の 複屈折は原系にくらぺて $46 \%$ も低下した。一方篮酸に より絹フィブロインを加水分解した残渣は $326^{\circ} \mathrm{C}$ 近边に 吸熱ピークを示した。この湿度は第 20 吸熱ピーク温度 とはぼ一致した。DTAK括いてベースラインからシフ 卜しはじめる温度， $T_{d}$ は霛囲気の生力の增加に従って 低温側に移行した。絹フィブロインの熱機械的測定の結
果から試料の急激な收縮は， $300^{\circ} \mathrm{C}$ 近辺で救とり， $\beta$ 構造よりランダムコイルの分子形態変化をともなうとと が明らか之なった。

これらの実験結果より測定雾围気の加圧によって現れ る低温側吸熱ピーク $\left(300^{\circ} \mathrm{C}\right)$ 絹フィブロインの無配向 $\beta$ 構造に，そして高温側吸熱ピーク $\left(326^{\circ} \mathrm{C}\right)$ は結晶性 $\beta$ 構造の熱分解隹上り扰とるあのと考えられた。

謝辞：高全DTAの測定に際し，始終ご指導いただき ました労翻省産業安全研究所の駒宮功額氏に樑謝の意を 示します。

\section{文献}

1）上田 成；熱則定，3，No.2，55（1976）

2）石川博，塚目益裕，士并詰功，近田淳雄、平林 㵖；繊学誌，28，91(1972)

3）平林潔，鈴木孝雄，奈倉正宜，石川博；分析譏 器, 12, No.7, 434 (1974)

4）平林 潔，范井三雄；日䃨雑，45，265(1976)

5) 石黑善夫，塚田益裕；高分子諭文集，34，No.7, $511(1977)$

6）塚田益裕；未発表データ 